\title{
Geriyatrik hemiplejik olgularda depresyon ve anksiyete düzeyi*
}

\author{
Ali Yavuz Karahan ${ }^{1}$, Ercan Kaydok ${ }^{2}$
}

\begin{abstract}
ÖZET:
Geriyatrik hemiplejik olgularda depresyon ve anksiyete düzeyi

Giriş: İnme sonrasında gelişen depresyon \%20-60 oranında bildirilmektedir ancak patogenezi henüz netlik kazanmamış konulardan birisidir. Çalışmamızda inmeli olgularda depresyon ve anksiyete düzeyini ortaya koymayı ve yaş faktörünün tabloya etkisini incelemeyi amaçladık.

Hastalar ve Yöntem: Seksen üç inme hastasının tanımlayıcı özellikleri kaydedildi. Hastaların bağımlıık düzeyi Fonksiyonel Bağımsızlık Ölçeği (FBÖ) ile, depresyon düzeyi Beck Depresyon Ölçeği (BDÖ) ile, anksiyete düzeyi Beck Anksiyete Ölçeği (BAÖ) ile değerlendirildi. Kognitif fonksiyonları değerlendirme amacıyla Mini Mental Test (MMT) kullanıldı. Elde edilen verilere yaşın etkisini ortaya koyabilmek için hastalar 65 yaş ve üzeri geriyatrik (GER) grup ve 65 yaş altı geriyatrik olmayan (NGER) grup olmak üzere ikiye ayrılarak istatistiksel karşılaştırmalar yapıldı.

Bulgular; GER grubunda 16'sı kadın $(\% 36,4)$, 28'i erkek $(\% 63,6)$ olmak üzere toplam 44 hasta, NGER grubunda 18'i kadın (\%46,2), 21'i erkek (\%53,8) olmak üzere toplam 39 hasta değerlendirildi. Yaş ortalaması GER grubunda 70,3 $\pm 6,1$, NGER grubunda 55,6 $\pm 6,4$ idi. GER grubunda ortalama FBÖ $65,8 \pm 22,5$, NGER grubunda ise $77,8 \pm 22,1$ idi. GER grubunda \%20,5 (9) hafif, \%47,7 (21) orta, \%2,3 (1) şiddetli düzeyde depresyon izlendi. NGER grubunda ise \%30,8 (12) hafif, \%30,8 (12) orta düzeyde depresyon bulguları izlendi. Gruplar arası karşılaştırmada geriyatrik grubun fonksiyonel bağımsızlık ve kognitif fonksiyon düzeyleri daha geride bulunurken daha ciddi düzeyde depresyon ve anksiyete bulguları gösterdiği izlendi.

Sonuç: Inme sonrası gelişen depresyon yaşam kalitesini ve rehabilitasyon sürecini olumsuz yönde etkileyebilecek sıkıı̆ı hiç de az olmayan önemli bir komorbid hastalıktır. Özellikle geriyatrik hastalarda sıkığının daha da fazla olabileceği akılda tutulmalıdır ve erken dönemde tanımlanarak tedavisine başlanmalıdır.
\end{abstract}

Anahtar kelimeler: Inme, geriatri, anksiyete, depresyon

\section{ABSTRACT: \\ Depression and anxiety levels in geriatric patients with hemiplegia}

Introduction: Post stroke depression is the one of the issues not yet well established on pathogenesis and reported $20-60 \%$ after stroke. We aimed to reveal the level of anxiety and depression in stroke patients and aimed to investigate the effect of the age factor table in our study.

Patients and Method: Descriptive characteristics of eighty-three stroke patients were recorded. The patients were evaluate with the Functional Independence Measure (FIM) for level of dependency, the Beck Depression Inventory (BDI) for the depression levels, the Beck Anxiety Inventory (BAI) for the anxiety levels, the Mini Mental Test (MMT) for evaluate the cognitive functions. To elucidate the effect of age, patients were divided two groups as geriatric group (GER) and non- geriatric group (NGER) and then statistical comparisons were done.

Results: Sixteen women (36.4\%) and 28 men (63.6\%) for a total of 44 patients in were evaluated GER group, 18 women $(46.2 \%)$ and 21 males $(53,8 \%)$ for a total of 39 patients were evaluated in NGER group. The mean age of GER group was $70.3 \pm 6.1$ and NGER group was 55.6 \pm 6.4 . The mean FIM of GER group was $65.8 \pm 22.5$ and NGER group was $77.8 \pm 22.1$. In GER group $20.5 \%$ mild, $47.7 \%$ moderate and $2.3 \%$ severe depression was observed. In NGER group $30.8 \%$ mild and $30.8 \%$ moderate depression was observed. Significantly lower levels of functional independence and cognitive function were observed and depression and anxiety were more serious levels in geriatric patients.

Conclusion: The process of post-stroke depression is not an uncommon comorbid disease which may adversely affect the quality of life and rehabilitation. That should be kept in mind especially in geriatric patients and early treatment should be initiated.

Key words: Stroke, geriatrics, anxiety, depression

Ş.E.E.A.H. Tıp Bülteni 2013;47(3):130-137
*Bu çalışmanın özeti 2012 Türk Geriatri Kongresi'nde poster olarak sunulmuştur.

'Uz. Dr., Konya Beyhekim Devlet Hastanesi, Fiziksel Tıp ve Rehabilitasyon Bölümü, Konya-Türkiye

Uz. Dr., Niğde Devlet Hastanesi, Fiziksel Tıp ve Rehabilitasyon Bölümü, Niğde-Türkiye

Yazışma Adresi / Address reprint requests to: Uz. Dr. Ali Yavuz Karahan, Yunusemre Mah. Nurani Sk. No: 3 Meram, Konya-Türkiye

Telefon / Phone: +90-538-692-1934

E-posta / E-mail:

ayk222@hotmail.com

Geliş tarihi / Date of receipt:

24 Şubat 2013 / February 24, 2013

Kabul tarihi / Date of acceptance: 4 Haziran 2013 / June 4, 2013 


\section{GíRiş}

Serebrovasküler olay (SVO), en sık görülen ciddi nörolojik hastalık olarak kabul edilmektedir. Morbiditeye yol açan hastalıklar arasında ilk sırada yer almaktadır (1). SVO'ya bağlı inme, hastalar, aileleri ve sağlık kurumları için uzun süreli emosyonel ve sosyoekonomik sorunlara yol açan önemli bir yetersizlik nedenidir $(1,2)$. Psikiyatrik bozukluklarda inmeli olgularda gelişebilecek komplikasyonlar arasında önemli bir yere sahiptir. Depresyon başta olmak üzere vasküler demans, mani, anksiyete bozuklukları, psikotik bozukluklar, apati, patolojik gülme ve ağlama krizleri inme ile ilişkilendirilebilen psikiyatrik hastalıklardır (2-4).

Depresyon ve anksiyete inme sonrası en sık gelişen psikiyatrik bozukluklardandır. İnme sonrası anksiyete bozukluğu olanların çoğuna depresyon eşlik edebilir (4-6). Yapılan çalışmalarda inme sonrası depresyon (ISD) sıklığı \%20-60 oranında bildirilmektedir. İnme sonrası ikinci haftada veya takip eden iki yıl içerisinde major ya da minör depresyon belirtileri görülebilmektedir. ISD'nin \%19-23 oranında major depresyon düzeyinde olabildiği gösterilmiştir $(5,6)$. Serebral iskemiye bağlı olarak ortaya çıkan nörokimyasal ve nörofizyolojik değişiklikler iSD'nin etiyolojisine yönelik çalışmaların temelini oluşturmaktadır ancak ISD henüz patogenezi netlik kazanmayan konulardan biridir $(7,8)$.

iSD hastalarda fonksiyonel durumu kötüleştiren ve mortaliteyi arttıran ciddi bir komplikasyondur (1-5). Ayrıca hastanın yaşam kalitesini ve iyileşme sürecini olumsuz yönde etkilemesine rağmen klinisyenler tarafından yeterince tanınıp tedavi edilememektedir $(1,7)$. İnme sonrası hastalarda iskemik beyin hasarına bağlı olarak ortaya çıkan bilişsel ve vejetatif bulgular ile depresif bulguların birbirinden ayırt edilememesi de tanısal güçlüğü artırmaktadır (7-9). ISD'nin erken dönemde tanınıp tedavi edilmesi etkin bir rehabilitasyon süreci için önemlidir $(8,9)$.

Bizde çalışmamızda inme sonrası hemipleji kliniği gelişen hastalarda yaş faktörünün hastaların fonksiyonel bağımsızlık düzeyleri ve kognitif fonksiyonlarına paralel olarak belirlenen depresyon ve anksiyete düzeylerine etkisini incelemeyi amaçladık.

\section{HASTALAR VE YÖNTEM}

Prospektif olarak planlanan çalışmaya inme sonrası hemipleji kliniği gelişen 83 hasta alındı. Rehabilitasyon programı öncesinde değerlendirilen hastaların tanımlayıcı özellikleri kaydedildi. Ayrıca hastaların bağımlılık düzeyi Fonksiyonel Bağımsızlık Ölçümü (FBÖ) ile, kognitif fonksiyon düzeyleri Mini Mental Test (MMT) ile, depresyon düzeyi Beck Depresyon Ölçeği (BDÖ) ile ve anksiyete düzeyi Beck Anksiyete Ölçeği (BAÖ) ile belirlendi. Elde edilen verilere yaşın etkisini ortaya koyabilmek için hastalar 65 yaş ve üzeri geriyatrik (GER) grup ve 65 yaş altı geriyatrik olmayan (NGER) grup olmak üzere ikiye ayrılarak istatistiksel karşılaştırmalar yapıldı.

Hastaların çalışmaya dahil edilme kriterleri; ilk kez SVO geçiren hastalar, SVO sonrasında hemipleji tablosu gelişen hastalar, SVO sonrası en az 3. haftasında olan hastalar ve yeterli düzeyde iletişim kurulabilen hastalar çalışmaya alındı.

Çalışmadan dışlama kriterleri; İnme öncesinde psikiyatrik ve kognitif problemler olanlar (psikiyatrist ve nörolog doktorlarca değerlendirilen hasta kayıtları ve hasta yakınlarından alınan bilgilerle), ilave bir başka merkezi sinir sistemi hastalığı olanlar, malignite tanısı olanlar, testlere uyumları açısından ileri derecede iletişim güçlüğü çeken hastalar çalışmaya dahil edilmemiştir.

Hastaların bağımlılık düzeyi FBÖ ile değerlendirildi. FBÖ, günlük yaşam aktivitelerini gerçekleştirmedeki fiziksel ve bilişsel yetersizlikleri, yardım ihtiyacını ve bakım yükünü ölçmektedir. Altı fonksiyon alanı değerlendiren (kendine bakım, sfinkter kontrolü, mobilite, hareket, iletişim ve sosyal bilişsellik) 18 maddeden oluşmaktadır. Bu maddeler motor-FBÖ (13 madde) ve bilişsel FBÖ (5 madde) olmak üzere iki kısımda incelenmektedir. Motor FBÖ, bilişsel maddeler sosyal etkileşimi, problem çözme ve hafızayı değerlendirmektedir. Her madde yardım miktarını belirten 7-puanlı Likert skalasında değerlendirilir (1=total yardım, 7 =total bağımsızlık). Değerlendirme gözleme dayalıdır yaklaşık 20 dakika sürmektedir (11). FBÖ'nün Türkçe uyarlaması mevcuttur (12).

Hastaların kognitif fonksiyonlarını değerlendirmek amacıyla MMT kullanıldı. MMT erişkinlerdeki bilişsel bozukluğun kantitatif olarak değerlendirilme- 
si amacıyla geliştirilmiştir. Oryantasyon, anlık ve kısa dönem hafıza, dikkat ve hesaplama, lisan ve praksi değerlendirilmektedir. MMT skorunun 23 veya altında olması bilişsel bozukluğa işaret etmektedir. MMT'nin duyarlılığını etkileyen en önemli değişken bilişsel bozukluğun düzeyidir $(13,14)$.

Depresyon düzeyini belirlemek amacıyla Beck Depresyon Ölçeği (BDÖ)kullanıldı. Bu ölçek depresyonda görülen bedensel, duygusal, bilişsel belirtileri ölçmektedir. Yirmi bir belirti kategorisini içeren kendini değerlendirme ölçeğidir (15). Alınacak en yüksek puan 63'tür. Toplam puanın yüksekliği depresyonun şiddetini gösterir (15). Beck ve arkadaşları tarafından geliştirilmiş olup ülkemizde geçerlilik ve güvenilirlik çalışması, Hisli tarafından yapılmıştır (16). Ölçekten alınan 0-9 puan; minimal, 10-16 puan; hafif, 17-29 puan; orta ve 30-63 puan; şiddetli düzeyde depresif belirtiler olarak yorumlanabilir $(16,17)$. BDÖ'den 17 puan ve üstü alan bir kişide psikiyatrik muayene ile depresyon saptanma olasılığı ortalama \%80, depresyonu olan bir bireyin 16 ve altında puan alma olasılığı ise ortalama \%30 olarak belirlenmiştir (16-18).
Anksiyete düzeyini belirlemek amacıyla Beck Anksiyete Ölçeği (BAÖ) kullanıldı. Bu ölçek bireyin yaşadığı anksiyete belirtilerinin sıklığını ölçmektedir $(19,20)$. Yirmi bir maddeden oluşan, 0-3 arası puanlanan Likert tipi bir kendini değerlendirme ölçeğidir $(19,20)$. Toplam puanın yüksekliği kişinin yaşadı̆̆ı anksiyetenin yüksekliğini gösterir $(19,20)$. Beck ve arkadaşları tarafından geliştirilmiş olup ülkemizde geçerlilik ve güvenilirlik çalışması yapılmıştır $(19,20)$. Ölçekten alınan 0-7 puan; minimal, 8-15 puan; hafif, 16-25 puan; orta ve 26-63 puan; şiddetli düzeyde depresif belirtiler olarak yorumlanabilir (19-21).

İstatistiksel inceleme SPSS 13.0 paket programı ile yapıldı. Parametrik değerlerin karşılaştırılmasında Student t testi, parametrik olmayan değerler için Ki-kare testi, normal dağılım göstermeyen sonuçları için Mann Whitney $U$ testi kullanıldı. Anlamlılık düzeyi olarak $\mathrm{p}<0.05$ kabul edildi.

\section{BULGULAR}

GER grubunda 44, NGER grubunda 39 hasta çalışmaya alındı. GER grubundaki hastaların yaşları 65-89

Tablo 1: Hastaların tanımlayıcı özellikleri

\begin{tabular}{|c|c|c|c|}
\hline & GER grup (n: 44) & NGER grup (n: 39) & $\mathbf{P}$ \\
\hline Yaş Ortalaması & $70,3 \pm 6,1$ & $55,6 \pm 6,4$ & 0,000 \\
\hline Cinsiyet & & & 0,365 \\
\hline Kadın & $\% 36,4(16)$ & $\% 46,2(18)$ & \\
\hline Erkek & $\% 63,6(28)$ & $\% 53,8(21)$ & \\
\hline Öğrenim durumu & & & 0,692 \\
\hline Okuma-yazma yok & $\% 20,5(9)$ & $\% 12,8(5)$ & \\
\hline İlk-ortaokul mezunu & $\% 52,3(23)$ & $\% 64,1(25)$ & \\
\hline Lise Mezunu & $\% 22,7(10)$ & $\% 17,9(7)$ & \\
\hline Üniversite Mezunu & $\% 4,5(2)$ & $\% 5,1(2)$ & \\
\hline \multicolumn{4}{|l|}{ İnme için Risk faktörü } \\
\hline Hipertansiyon & $\% 70,5(31)$ & $\% 76,9(30)$ & 0,505 \\
\hline Diyabetes Mellitus & $\% 31,8(14)$ & $\% 25,6(10)$ & 0,536 \\
\hline Hiperkolestrolemi & $\% 18,2(8)$ & $\% 17,9(7)$ & 0,978 \\
\hline Koroner arter hastalığı & $\% 22,7(10)$ & $\% 25,6(10)$ & 0,757 \\
\hline Atrial Fibrilasyon & $\% 22,7(10)$ & $\% 10,3(4)$ & 0,130 \\
\hline Aile öyküsü & $\% 11,4(5)$ & $\% 10,3(4)$ & 0,747 \\
\hline Sigara kullanımı & $\% 22,7(10)$ & $\% 17,9(7)$ & 0,060 \\
\hline Etkilenen hemisfer & & & 0,276 \\
\hline Sol & $\% 47,7(21)$ & $\% 35,9(14)$ & \\
\hline Sağ & $\% 52,3(23)$ & $\% 64,1(25)$ & \\
\hline İnme tipi & & & 0,190 \\
\hline İskemik inme & $\% 88,6(39)$ & $\% 74,4(29)$ & \\
\hline İntraparankimal kanama & $\% 11,4(5)$ & $\% 23,1(9)$ & \\
\hline Subaraknoid kanama & - & & $\% 2,6(1)$ \\
\hline İnme sonrası geçen süre (Gün) & $73,5 \pm 28,7$ & $69,6 \pm 25,1$ & 0,753 \\
\hline
\end{tabular}

GER: Geriyatrik NGER: Geriyatrik olmayan 


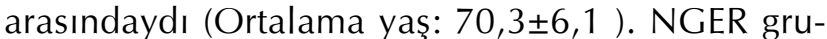
bundaki hastaların yaşları ise 31-64 arasındaydı

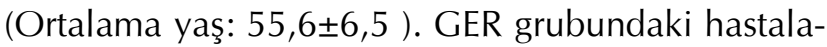
rın \%36,4 (16)'ü kadın, \%63,6 (28)'sı erkek, NGER grubundaki hastaların ise \%46,2 (18)'si kadın, \%53,8 (21)'i erkekti ve grupların cinsiyet dağılımları arasında anlamlı düzeyde bir fark yoktu (P: 0,365) (Tablo $1)$.

GER grubundaki hastaların \%20,5 (9)'i okuma yazma bilmiyordu. Hastaların \%52,3 (23)'ü ilkortaokul, \%22,7 (10)'si lise ve \%4,5 (2)'i üniversite mezunu idi. NGER grubundaki hastaların ise $\% 12,8$ (5)'i okuma yazma bilmiyordu. Hastaların \%64,1 (25)'i ilk-ortaokul, \%17,9 (7)'u lise ve \%5,1 (2)'i üniversite mezunu idi. Grupların Öğrenim durumu dağılımları arasında anlamlı düzeyde bir fark yoktu (P:0,692) (Tablo 1).

Sorgulanan inme risk faktörleri değerlendirildiğinde; GER grubundaki hastaların \%70,5 (31)'inde hipertansiyon, \%31,8 (14)'inde diyabetes mellitus, $\% 18,2$ (8)'inde hiperkolestrolemi, \%22,7 (10)'inde koroner kalp hastalığı, \%22,7 (10)'inde atrial fibrilasyon, \%11,4 (5)'ünde ailede inme öyküsü ve \%22,7 (10)'inde sigara kullanımı mevcuttu. NGER grubundaki hastaların ise \%76,9 (30)'unda hipertansiyon, $\% 25,6$ (10)'sında diyabetes mellitus, \%17,9 (7)'unda hiperkolestrolemi, \%25,6 (10)'sında koroner kalp hastalığı, \%10,3 (4)'ünde atrial fibrilasyon, \%10,3 (4)'ünde ailede inme öyküsü ve \%17,9 (7)'unda sigara kullanımı mevcuttu. Grupların sorgulanan inme için risk faktörleri dağılımları arasında anlamlı düzey- de bir fark yoktu (Tablo 1).

GER grubundaki hastaların \%88,6 (39)'sında iskemik inme, \%11, 4 (5)'ünde ise intraparankimal kanama tablosu sonrası hemipleji gelişmişti. NGER grubundaki hastaların ise \%74,4 (29)'ünde iskemik inme, \%23,1 (9)'inde intraparankimal kanama, \%2,6 (1)'sında subaraknoid kanama tablosu sonrası hemipleji gelişmişti. Grupların SVO nedenlerinin dağılımları arasında anlamlı düzeyde bir fark yoktu (P: 0,190) (Tablo 1).

GER grubundaki hastaların \%47,7 (21)'sinde sol, \%52,3 (23)'ünde sağ hemisfer etkilenmişti. NGER grubundaki hastaların ise \%35,9 (14)'unda sol, \%64,1 (25)'inde sağ hemisfer etkilenmişti ve gruplar arasında etkilenen hemisfer tarafı açısından anlamlı bir fark oluşmamaktaydı (P: 0,276) (Tablo 1).

GER grubundaki hastalarda, SVO sonrası geçen süre 30-165 gün arasında değişmekteydi ve ortalama olarak: $73,5 \pm 28,7$ gün idi. NGER grubunda ise SVO sonrası geçen süre 21-126 gün arasında değişmekteydi ve ortalama olarak: $69,6 \pm 25,1$ gün idi. SVO sonrası geçen süre açısından gruplar arasında anlamIı bir fark yoktu (P: 0,753) (Tablo 1).

GER grubunda kognitif FBÖ ortalama olarak $20,8 \pm 7,4$, motor FBÖ ortalama olarak 45,0 $0 \pm 16,2$ ve toplam FBÖ ortalama olarak $65,8 \pm 22,5$ idi. NGER grubunda kognitif FBÖ ortalama olarak 24,2 $\pm 6,3$, motor $\mathrm{FBÖ} \mathrm{ortalama} \mathrm{olarak} 53,5 \pm 17,1$ ve toplam FBÖ ortalama olarak $77,8 \pm 22,1$ idi. Kognitif, motor ve toplam FBÖ değerlendirmelerinde gruplar arasında anlamlı düzeyde fark mevcuttu (Tablo 2).

Tablo 2: Elde edilen verilerin gruplar arası karşılaştırılması

\begin{tabular}{lccc}
\hline & GER grup (n: 44) & NGER grup (n: 39) & P \\
\hline FBÖ toplam & $65,8 \pm 22,5$ & $77,8 \pm 22,1$ & 0,022 \\
FBÖ motor & $45,0 \pm 16,2$ & $53,5 \pm 17,1$ & 0,021 \\
FBÖ kognitif & $20,8 \pm 7,4$ & $24,2 \pm 6,3$ & 0,033 \\
Mini mental test & $17,9 \pm 3,9$ & $19,8 \pm 5,0$ & 0,034 \\
BDÖ Toplam & $15,7 \pm 6,4$ & $12,9 \pm 5,6$ & 0,042 \\
BDI 0-9 & $\% 20,5(9)$ & $\% 38,4(15)$ & \\
BDI 10-16 & $\% 29,5(13)$ & $\% 30,8(12)$ & \\
BDI 17-29 & $\% 47,7(21)$ & $\% 30,8(12)$ & 0,075 \\
BDI 30-63 & $\% 2,3(1)$ & \\
BAÖ Toplam & $12,8 \pm 6,5$ & $10,1 \pm 6,2$ & \\
BAl 0-7 & $\% 6,8(3)$ & $\% 10,3(4)$ & \\
BAl 8-15 & $\% 36,4(16)$ & $\% 56,4(22)$ & \\
BAl 16-25 & $\% 50,0(22)$ & $\% 28,2(11)$ & \\
BAI 26-63 & $\% 6,8(3)$ & $\% 5,1(2)$ & \\
\hline
\end{tabular}

GER: Geriyatrik NGER: Geriyatrik olmayan FBÖ: Fonksiyonel Bağımsızlık Ölçümü BDÖ: Beck Depresyon Ölçeği BAÖ: Beck Anksiyete Ölçeği 
Tablo 3: Verilerin cinsiyete ve etkilenen hemisfere göre grup içi karşılaştırılması

\begin{tabular}{|c|c|c|c|c|}
\hline & FBÖ toplam & Mini Mental Test & BDÖ & BAÖ \\
\hline \multicolumn{5}{|l|}{ GER Grup (n:44) } \\
\hline \multicolumn{5}{|l|}{ Cinsiyet } \\
\hline Kadın (n:16) & $63,0 \pm 14,1$ & $17,5 \pm 3,8$ & $15,8 \pm 4,7$ & $12,3 \pm 4,7$ \\
\hline Erkek (n:28) & $67,4 \pm 26,2$ & $18,1 \pm 4,0$ & $15,7 \pm 7,3$ & $13,1 \pm 7,4$ \\
\hline \multicolumn{5}{|c|}{ Etkilenen Hemisfer } \\
\hline Sağ (n:23) & $68,6 \pm 21,8$ & $18,4 \pm 3,4$ & $15,0 \pm 6,5$ & $12,1 \pm 6,3$ \\
\hline Sol (n:21) & $63,3 \pm 23,3$ & $17,3 \pm 4,3$ & $16,5 \pm 6,3$ & $13,4 \pm 6,7$ \\
\hline \multicolumn{5}{|l|}{ NGER Grup (n:39) } \\
\hline \multicolumn{5}{|l|}{ Cinsiyet } \\
\hline Kadın (n:18) & $78,0 \pm 22,2$ & $20,0 \pm 5,7$ & $14,0 \pm 5,8$ & $11,5 \pm 6,3$ \\
\hline Erkek (n:21) & $77,6 \pm 22,6$ & $19,7 \pm 4,5$ & $12,0 \pm 5,5$ & $9,0 \pm 6,3$ \\
\hline \multicolumn{5}{|c|}{ Etkilenen Hemisfer } \\
\hline Sağ $(n: 25)$ & $78,2 \pm 20,8$ & $20,4 \pm 4,8$ & $12,7 \pm 5,6$ & $9,9 \pm 5,5$ \\
\hline Sol (n:14) & $73,0 \pm 22,9$ & $19,1 \pm 4,4$ & $13,9 \pm 5,5$ & $11,3 \pm 6,8$ \\
\hline
\end{tabular}

GER: Geriyatrik, NGER: Geriyatrik olmayan, FBÖ: Fonksiyonel Bağımsızlık Ölçümü, BDÖ: Beck Depresyon Ölçeği, BAÖ: Beck Anksiyete Ölçeği

Ortalama MMT GER grubunda 17,9 $\pm 3,9$, NGER grubunda ise 19,8 $\pm 5,6$ idi ve gruplar arsında anlamlı düzeyde fark mevcuttu (P: 0,034) (Tablo 2).

GER grubunda ortalama BDÖ 15,7 $\pm 6,4$ olarak bulundu. Bu grupta hastaların \%20,5 (9)'nin minimal, \%29,5 (13)'nin hafif, \%47,7 (21)'sinin orta ve $\% 2,3$ (1)'ünün şiddetli düzeylerde depresif belirtiler gösterdiği saptandı. Bu gruptaki olguların \%50,0 (22)'sinin, BDÖ'sü 17 ve üzerinde idi. NGER grubun-

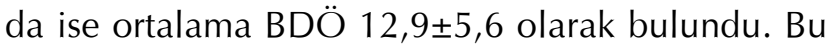
gruptakilerin depresif belirtileri \%38,4 (15)'ünde minimal, \%30,8 (12)'inde hafif ve \%30,8 (12)'inde orta şiddet düzeylerindeydi. İkinci gruptaki olguların \%30,8 (112)'inin, BDÖ’sü 17 ve üzerindeydi. Grupların BDÖ düzeyleri arasında istatistiksel olarak anlamlı düzeyde fark mevcuttu (P: 0,042) (Tablo 2).

Birinci gruptaki hastaların ortalama BAÖ 12,8 $8 \pm 6,5$ olarak bulundu. Bu gruptakilerin \%6,8 (3)'inin minimal, \%36,4 (16)'ünün hafif, \%50,0 (22)'sinin orta ve $\% 6,8$ (3)'inin şiddetli düzeylerde anksiyete belirtileri gösterdiği belirlendi. İkinci gruptaki hastaların ortalama BAÖ 10,1 $\pm 6,2$ olarak bulundu. Bu gruptaki hastaların \%10,3 (4)'ü minimal, \%56,4 (22)'ü hafif, $\% 28,2(11)^{\prime}$ si orta ve \%5,1 (2)'i şiddetli düzeylerde anksiyete belirtileri gösterdi. BAÖ düzeyleri bakımından gruplar arasındaki fark anlamlı değildi (P: 0,075) (Tablo 2).

Grup içi değerlendirmelerde GER grubundaki

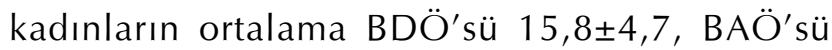

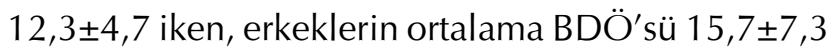

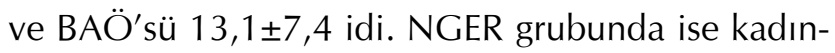

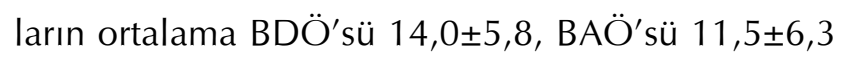
iken, erkeklerin ortalama BDÖ'sü $12,0 \pm 5,5$ ve BAÖ'sü 9,0 66,3 idi. Grup içi ve cinsiyete göre yapılan karşılaştırmada cinsiyetler arasında BDÖ ve BAÖ açısından anlamlı düzeyde fark yoktu (Tablo 3).

Grup içi değerlendirmelerde GER grubunda sağ hemisferi etkilenmiş olan hastaların ortalama BDÖ'sü $15,0 \pm 6,5$, BAÖ'sü 12,1 $\pm 6,3$ iken, sol hemisferi etkilenmiş olan hastaların ortalama BDÖ'sü $16,5 \pm 6,3$ ve BAÖ'sü 13,4 46,7 idi. NGER grubunda ise sağ hemisferi etkilenmiş olan hastaların ortalama BDÖ'sü $12,7 \pm 5,6$, BAÖ'sü 9,9 $9 \pm 5,5$ iken, sol hemisferi etkilenmiş olan hastaların ortalama BDÖ'sü $13,9 \pm 5,5$ ve BAÖ'sü 11,3 $\pm 6,8$ idi. Grup içi ve etkilenen hemisfere göre yapılan karşılaştırmada sağ veya sol hemisfer tutulumu olan hastalar arasında BDÖ ve BAÖ açısından anlamlı düzeyde fark yoktu (Tablo 3).

\section{TARTIŞMA}

İnme, Parkinson hastalığı, demans, multipl skleroz, epilepsi ve huntington hastalığı gibi kortikal ve/ veya subkortikal nörolojik hastalıklarda, limbik-kortikalstriatal-pallidal-talamik nöroanotomik yolak gibi emosyon kontrolünde önemli bölgelerin etkilenmesi sonucunda depresyon sıklığı artmıştır (5-7).

Farklı çalışmalarda iSD sıklığı \%30-50 aralığında bulunmuştur. İnme sonrası ilk altı ayda iSD sıklığının \%9-34 olduğu ancak iki yıllık izlem sonrasında bu oranın \%50'lere kadar çıktığı belirtilmiştir $(9,10,22)$. Ülkemizde yapılan çalışmalarda Dilek ve ark. (6) 
inme sonrası erken dönemde $\% 42,5$ oranında iSD, Altındağ ve ark. ise inme sonrası geç dönemde \%48,7 oranında major depresyon bildirmişlerdir (23). Müftüoğlu ve ark. inmeli hastalarda depresyon ve anksiyete skor ortalamalarının Türk popülasyonu için bildirilenden daha yüksek olduğunu göstermişlerdir (24). Çalışmamızın sonuçlarında literatürle uyumlu olarak inme sonrası erken dönemde olan 83 hastanın 34 $(\% 40,9)^{\prime}$ ünde, BDÖ 17 ve üzerindeydi. Ayrıca BAÖ hastaların $39(\% 46,9)^{\prime}$ unda 16 ve üzerinde saptandı.

iSD'nin etiyolojisini açıklamaya yönelik yapılan çalışmalarda özellikle inme sonrası ortaya çıkan yetersizlik tablosuna verilen psikolojik yanıt ve beyinde duygulanımla ilgili alanlarda oluşan lokal hasar üzerinde durulmaktadır $(25,26)$. Ayrıca inme için önemli risk faktörleri olan; koroner arter hastalı̆̆ı, konjestif kalp yetmezliği ve diyabetes mellitus gibi durumlarda da depresyon sıklığının arttığı ve antihipertansif ilaç kullanımının da depresif belirtilere yol açabileceği bilinmektedir $(4,5,26)$. Tüm bunların birlikteliği iSD gelişmesini kolaylaştırıcı veya tetikleyici olabilir (26). Ayrıca hastanın yaşı, cinsiyeti, eğitim düzeyi, inme öncesi var olan psikiyatrik hastalıklar, etkilenen bölgenin lokalizasyonu gibi faktörler isD gelişimi üzerinde etkileri araştırılan konulardır (26). Günümüzde halen íSD'nin etiyolojisini açıklayabilen tutarlı bir model bulunmamaktadır $(3,22,26)$.

Bizim çalışmamızda inme için önemli risk faktörlerinden olan hipertansiyon, diabetes mellitus, hiperkolestrolemi, koroner arter hastalığı, atrial fibrilasyon, aile öyküsü ve sigara kullanımı sıklığı belirlendi. Risk faktörlerinin sıklığı açısından gruplar arası değerlendirmede anlamlı bir fark yoktu. Ayrıca daha önceki yaşantısında psikiyatrik problemleri olan hastaların çalışmaya alınmaması ve çalışmaya alınan hastaların öğrenim durumları ve cinsiyet dağılımı açısından gruplar arası anlamlı bir fark olmayışı çalışmanın tutarlılığı açısından olumlu bir sonuçtu.

İnme sonrası geçen süreye bağlı olarak depresif semptomlar erken ve geç dönemde farklılıklar gösterebilmektedir $(24,26)$. Erken dönemde ortaya çıkan depresyonda otonomik ve vejetatif belirtiler daha fazla görülürken geç dönemde hem vejetatif hem de psikolojik belirtilerin bir arada yer aldığı belirti kümeleri görülebilir (26). Tateno ve ark. inme sonrası ilk altı ayda ortaya çıkan depresyonu erken, on ikinci aydan sonra ortaya çıkan depresyonu geç iSD olarak sınıflamış ve erken dönem minör depresyonda sosyal işlevselliğin bozulduğunu, melankolik, vejetatif ve psikolojik belirtilerin daha sık görüldügüüü bildirmişlerdir (27). Çalışmamızda inme sonrası geçen süre GER grubunda ortalama 73,5 $\pm 28,7$ gün, NGER grubunda ortalama $69,6 \pm 25,1$ gün idi ve gruplar arasında istatistiksel düzeyde fark yoktu.

Duygudurum bozukluklarının kadınlarda erkeklere oranla iki kat daha fazla görüldügü bilinmektedir. Biyolojik faktörlere dayandırılan bu durumun iSD içinde geçerli olabileceği düşünülerek iSD'de cinsiyetin etkisi ortaya konmaya çalışılmıştır $(26,28,29)$. Çalışmaların bir kısmı özellikle major depresyon olmak üzere isD'nin kadınlarda daha sık olduğunu bildirirken, cinsiyet ile iSD arasında ilişki olmadığını savunan çalışmalarda vardır (28-34). Bizim çalışmamızda grup içi yapılan değerlendirmelerde her iki grupta da kadınlarda hem BDÖ hem de BAÖ daha yüksek bulundu ancak fark istatistiksel olarak anlamIı düzeyde değildi.

Yapılan çalışmalarda inme sonrası depresyonun, inme sonrası oluşan lezyon lokalizasyonu ile ilişkisi üzerinde durulmuştur. Özellikle sol frontal ve sağ posterior lokalizasyonlu lezyonların depresyon gelişimi için daha riskli olduğu belirlenmiştir (35-37). Ancak yine birçok çalışmada lezyon lokalizasyonu ile iSD arasında bir ilişki saptanamamıştır $(25,30,32,34,38,39)$. Bizim çalışmamızda grup içi yapılan değerlendirmelerde her iki grupta da sol hemisferi etkilenmiş olan hastalarda hem BDÖ hem de BAÖ daha yüksek bulundu ancak fark istatistiksel olarak anlamlı düzeyde değildi.

Birçok çalışmada yaşın, inme sonrası fonksiyonel sonucu olumsuz etkilediği bildirilmiştir. Alexander inme başlangıç şiddetini ve yaşı, fonksiyonel iyileşme için en güçlü göstergeler olarak bildirmiştir (40). Kotila ise yaşın 65 ve üzerinde olmasının rehabilitasyon sürecine olumsuz etkileri olduğunu göstermiştir (38). Yine ileri yaşın inmeli hastalarda daha fazla dizabiliteye ve mortalite neden olduğu gösterilmiştir $(1,2,38)$. Patel ve arkadaşları da inme sonrası kognitif bozuklukların yaş ve düşük sosyoekonomik düzey ile ilişkili olduğunu belirtmişlerdir (41). Yapılan çalışmalar inmeli hastalarda ve sağlıklı kişilerde beklenen, ileri yaşlarda azalan kognitif fonksiyonların dep- 
resif duygudurum ile ilişkisini saptamışlardır $(31,35,37)$. Hastaların kognitif fonksiyon ve duygudurumlarının önemli bir yönü bu fonksiyonların hastanın günlük yaşam aktiviteleri performanslarına, rehabilitasyon sonuçlarına etkili olmasıdır (31). Çin'de yapılan bir popülasyon çalışmasında inmeli hastalarda depresif semptom skorları ile hastaların günlük yaşam aktiviteleri ve yaşı arasında önemli ilişki saptanmıştır (42). Ayrıca ileri yaşın depresyon için risk faktörü olduğu da belirtilmiştir $(25,26,31)$. Morris ve ark. ise ileri yaşın ISD gelişimi için risk faktörü olduğunu saptamışlardır (43). Bizim çalışmamızda da literatür ile uyumlu olarak FBÖ ile hesaplanan fonksiyonel bağımsızlık düzeyi ve MMT ile hesaplanan kognitif fonksiyonlar geriatrik grupta anlamlı düzeyde daha geriydi ve yine geriatrik hastalarda BDÖ ortalamaları geriyatrik olmayan inmeli hastalara göre istatistiksel olarak anlamlı düzeyde daha yüksekti. Literatürde bazı çalışmaların sonuçlarında ise yaş ile ISD arasında herhangi bir ilişki ortaya konamamıştır $(6,34)$.

\section{KAYNAKLAR}

1. Turhan N. Factors effective on prognosis in patients with stroke. J PMR Sci 2006;9(suppl):3-4.

2. Brandstater ME. Stroke rehabilitation. In: DeLisa JA, Gans BM, eds. Rehabilitation Medicine. Third Ed. Philadelphia: LippincottRaven Publishers, 1998. pp 1165-1189.

3. Goldstein LB, Adams $R$, Alberts MJ, et al. Primary prevention of ischemic stroke: a guideline from the American Heart Association/American Stroke Association Stroke Council: Stroke. 2006; 37:1583-633.

4. Karamustafalıoğlu $O$, Yumrukçal $H$. Depresyon ve anksiyete bozuklukları Ş.E.E.A.H. Tıp Bülteni 2011;45(2):65-74.

5. Çakır S. Genel Tıpta Depresyon. Klinik gelişim 2009;22(4):61-5.

6. Dilek A, Karataş M, Erkan H, Çetin N, Akman MN. PostStroke Depression; Relationship to Functional Impairment and Rehabilitation Outcome Turk J Phys Med Rehab 2005;51(4):1202.

7. Chemerinski E, Robinson $R$. The neuropsychiatry of stroke. Psychosomatics 2000;41:5-14.

8. Ranga KK, Mahlon D, Helena K, et al. Comorbidity of depression with other medical diseases in the elderly. Biological Psychiatry 2002;52:559-88.

9. Astrom M, Adolfsson R, Asplund K. Major depression in stroke patients. A 3-year longitudinal study. Stroke 1993; 24: 976-982.

10. Morris PL, Robinson RG, Andrzejewski P, Samuels J, Price TR. Association of depression with 10-year poststroke mortality. Am J Psychiatry 1993;150:124-129.

11. Voll $R$, Krumm B, Schweisthal B. Functional independence measure (FIM) as assessing outcome in medical rehabilitation of neurologically ill adolescents. Int J Rehabil Res 2001;24:123-31.

\section{SONUÇ}

İnme sonrası hemipleji kliniği gelişmiş olan, geriatrik ve geriatrik olmayan hastalarda prospektif olarak yaptığımız çalışmada, GER grubunun fonksiyonel bağımsızlık düzeyi ve kognitif fonksiyonlar açısından NGER grubuna göre geri kaldığını ve yine GER grubunda daha yüksek oranda depresif belirtilerin görüldüğü izlendi. Grup içi yapılan değerlendirmelerde kadınlarda ve sol hemisferi etkilenenlerde BDÖ ve BAÖ ortalamaları daha yüksek bulunsa da istatistiksel olarak anlamlı bir fark izlenmedi.

İnme sonrası dönemde, iSD sıklığının hiç de az olmadığı ve erken dönemde iskemik hasara bağlı ortaya çıkan bulgular ile depresyonun ayrımında ortaya çıkan güçlüklerin de ayırıcı tanı zorluklarına neden olduğu unutulmamalıdır. Ayrıca inme sonrası depresyonun yaşam kalitesini olumsuz yönde etkilediği ve mortaliteyi arttırdığı göz önünde bulundurulduğunda, hastalığın doğru tanı ve tedavisi bir kat daha önem kazanmaktadır.

12. Küçükdeveci AA, Yavuzer $G$, Elhan AH, Sonel B, Tennant A. Adaptation of the Functional Independence Measure for use in Turkey. Clin Rehabil 2001;15:311-9.

13. Küçükdeveci AA, Kutlay S, Elhan AH, Tennant A. Preliminary study to evaluate the validity of the mini-mental state examination in a normal population in Turkey. Int J Rehabil Res 2005;28:779.

14. Elhan AH, Kutlay S, Küçükdeveci AA, et al. Psychometric properties of the Mini-Mental State Examination in patients with acquired brain injury in Turkey. J Rehabil Med2005;37:306-11.

15. Beck, A.T., Ward, C.H., Mendelson, M., Mock, J., Erbaugh, J. An Inventory For Measuring Depression. Archives Of General Psychiatry 1961;4:53-63.

16. Hisli, N. Beck Depresyon Envanterinin Geçerliliği Üzerine Bir Çalışma. Turkish Journal Of Psychology 1987;6:118-22.

17. Kılınç S, Torun F. Türkiye'de Klinikte Kullanılan Depresyon Değerlendirme Ölçekleri Dirim Tıp Gazetesi 2011;86(1):39-47.

18. Aydemir Ö, Köroğlu E. Psikiyatride Kullanılan Klinik Ölçekler. 4. Baskı. Ankara: HYB Basın Yayın, 2009;21-30.

19. Beck AT, Epstein N, Brown G, Steer RA. An inventory for measuring clinical anxiety: Psychometric properties. J Consult Clin Psychol, 1988;56:893-7.

20. Ulusoy M, Şahin N, Erkman H. Turkish Version of The Beck Anxiety Inventory: psychometric Properties. J Cognitive Psychotherapy: Int Quaterly, 1998;12:28-35.

21. Keedwell P, Snaith RP. What do anxiety scales measure? Acta Psychiatr Scand 1996;93(3):177-80. 
22. Fruehwald S, Loffler H, Eher R. Relationship between depression, anxiety and quality of life: a study of stroke patients compared to chronic low back pain and myocardial ischemia patients. Psychopat 2001;34:50-6.

23. Altındağ Ö, Soran N, Demirkol A, Özkul MY. The Association Between Functional Status, Health Related Quality of Life and Depression After Stroke Turk J Phys Med Rehab 2008;54:89-91.

24. Müftüoğlu M, Bahşi YZ, Dereboy F Ertürk Ö, Dereboy Ç. Strok hastalarında depresyon, anksiyete ve aleksitimi bulgularının araştırılması. Düşünen Adam 1995;8(2):24-6.

25. Gainotti G, Azzoni A, Marra C. Frequency, phenomenology, and anatomical-clinical correlates of major post-stroke depression. $\mathrm{Br}$ J Psychiatry 1999; 175:163-7.

26. Altınbaş K. Oral T. Soysal A. Arpacı B. Inme sonrası depresyon Klinik Psikiyatri 2006;9:148-53.

27. Tateno A, Kimura $M$, Robinson RG. Phenomenological charecteristics of poststroke depression. Am J Geriatr Psychiatry 2002;10:575-82.

28. Paradiso S, Ohkubo T, Robinson RG. Vegetative and psychological symptoms associated with depressed mood over the first two years after stroke. Int J Psychiatry Med 1997;27:137-57.

29. Sharpe $M$, Hawton $K$, House A, et al. Mood disorders in longterm survivors of stroke: associations with brain lesion location and volume. Psychol Med 1990;20(4):815-28.

30. Benbir G, Gözükırmızı E. Akut Serebrovasküler Hastalık Sonrası Erken Dönemde Depresyon New Symposium Journal 2006;44(1):44-8.

31. Burvill P, Johnson G, Jamrozik K, Anderson C, Stewart-Wynne E. Risk factors for poststroke depression. Int J Geriatr Psychiatry 1997;12(2):219-26.

32. Öncel Ç, Kalaycı D, Cura Ç, Can I, Kalkancı Ö. Akut Inmeli Hastalarda Depresyon Ve Kognitif Bozukluk Journal Of Turkish Cerebrovascular Diseases 2009;1:7-11.
33. Kellermann M, Fekete I, Gesztely R, Csiba L, Kollar J, Sikula J, Bereczki D. Screening for depressive symptoms in acute phase of stroke. General Hospital Psychiatry 1999;21:116-21.

34. Nys GM, van Zandvoort MJ, van der Worp HB, de Haan EH, de Kort PL, Kappelle LJ. Early depressive symptoms after stroke: neuropsychological correlates and lesion characteristics. J Neurol Sci 2005;228:27-33.

35. Robinson RG, Kubos KL, Starr $L B$ ve ark. Mood changes in stroke patients: Relationship to lesion location. Compr Psychiatry, 1983;24:555-66.

36. Robinson RG, Kubos KL, Starr LB ve ark. Mood disorders in stroke patients:importance of location of lesion. Brain 1984;107:81-93.

37. Shimoda K, Robinson RG. The relationship between poststroke depression and lesion location in long-term followup. Biol Psychiatry 1999;45:187-92.

38. Kotila $M$, Numminen $H$, Waltimo $O$, Kaste $M$. Depression after stroke: results of the Fin Stroke Study. Stroke 1998;29:368-72.

39. Yalıman A. Eskiyurt N. Vural M. Dönmez M. Çeşme F. Demirci $S$, et Al. Cognitive Function And Depressive Mood Change After Cerebrovascular attack. Turk J Geriatr 2004;7(4):211-6.

40. Alexander MP. Stroke rehabilitation outcome. A potential use of predictive variables to establish levels of care. Stroke 1994;25:128-34.

41. Patel MD, Coshall C, Rudd AG, Wolfe CD. Cognitive impairment after stroke: clinical determinants and its associatiations with long-term stroke outcomes. I Am Geriatr Soc 2002;50:700-6.

42. Fuh JL, Liu HC, Wang SJ, Liu CY, Wang PN. Poststroke deprression among Chinese elderly in a rural community. Stroke 1997;28:1126-9.

43. Morris $P$, Robinson $R$, Raphael B, Bishop D. The relationship between the perception of social support and poststroke depression in hospitalized patients. Psychiatry 1991;54:306-16. 